\title{
Connecting societal issues, users and data. Scenario-based design of open data platforms
}

\author{
Erna Ruijer ${ }^{\mathrm{a}, *}$, Stephan Grimmelikhuijsen ${ }^{\mathrm{a}}$, Michael Hogan ${ }^{\mathrm{b}}$, Sem Enzerink ${ }^{\mathrm{a}}$, Adegboyega Ojo ${ }^{\mathrm{b}}$, \\ Albert Meijer ${ }^{a}$

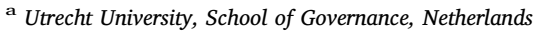 \\ b National University of Ireland, Galway, Ireland
}

\section{A R T I C L E I N F O}

\section{Keywords:}

Open data platform

User requirements

Scenario-based design

Societal issues

\begin{abstract}
A B S T R A C T
Governments around the world make their data available through platforms but, disappointingly, the use of this data is lagging behind. This problem has been recognized in the literature and to facilitate use of open datasets, scholars have focused on identifying general user requirements for open data platform design. This approach however fails to take into account the variation of open data practices and specific contexts of usage. This study, therefore, argues that next to general requirements: we also need to collect context-specific user requirements for open data platforms. We take different societal issues as the starting point for open data platform design. To illustrate the value of this context-specific approach, we apply scenario-based design methodology in the Province of Groningen in The Netherlands. The results show that different scenarios result partly in similar but also partly in different user requirements, leading to a deeper and richer understanding of user requirements. We conclude that a context-specific approach thereby connecting data, users and societal issues can be used to guide government agencies and designers in efforts to develop open data platforms that actually meet the needs of citizens.
\end{abstract}

\section{Introduction}

Governments all around the world have started to make their datasets available to the public with high expectations of benefits to society (Dawes, Vidiasova, \& Parkhimovich, 2016; Susha, Grönland, \& Janssen, 2015). Open data platforms aim to foster democratic processes by promoting transparency through the publication of government data and they aim to provide opportunities for innovation through the development of new products and services (Dawes \& Helbig, 2010; Janssen, 2011; Lourenço, 2015). A key benefit of these platforms is that they make it easier for citizens to articulate their opinions and interact with public administrators and political representatives on societal issues (Wijnhoven, Ehrenhard, \& Kuhn, 2015, p. 30; Taylor et al., 2014). However the actual use of open government data is lagging behind (Attard, Orlandi, Scerri, \& Auer, 2015; Dawes et al., 2016; Hossain, Dwivedi, \& Rana, 2015; Janssen, Charalabidis, \& Zuiderwijk, 2012; Safarov, Meijer, \& Grimmelikhuijsen, 2017; Wang \& Lo, 2016).

In order to stimulate and facilitate the use of open data platforms, scholars have formulated a range of general user requirements, such as usability, timeliness and value, (Jaeger, Bertot, \& Shilton, 2012;
Lourenço, 2015; Zuiderwijk \& Janssen, 2014a, 2014b) and data quality (Vetro et al., 2016). These studies either take data, portals, or users as point of departure for analysis, but fail to take into account the specific context of open data use (Meijer, Hoog, Steen, \& Scherpeniss, 2012). The basic assumption of open data is that data can be used for every purpose and that patterns of usage cannot be predicted (Janssen, 2011). This assumption, however, may actually impair usage since there may not be a 'match' between context-specific user requirements and data provision. Attention to context-specific user requirements may therefore contribute to the usage of open data. This study takes a specific purpose, a context-specific issue, as point of departure for open data platform design. Our context-specific approach builds on participatory and problem driven open data models (Sieber \& Johnson, 2015; Susha et al., 2015) and implies incorporating a contextual frame in the collection of user requirements. The contextual frame consists of real-life or societal issues around different types of utilizations by different users.

The aim of this study is two-fold. First of all, this study explores the value of a context-specific approach for the collection of user requirements for platform design. Different societal issues might imply the involvement of different users with different information needs (Susha

\footnotetext{
* Corresponding author at: Utrecht University, School of Governance, Bijlhouwerstraat 6, 3511 ZC Utrecht, Netherlands.

E-mail address: h.j.m.ruijer@uu.nl (E. Ruijer).
} 
et al., 2015) and different social interaction and usability needs. Second, this study proposes a collective intelligence scenario-based design methodology to collect context-specific user needs. This methodology builds upon the service design literature and uses collective intelligence methodologies (Warfield, 2006), scenario-based design (Caroll, 2000) and agile user story (Cohn, 2004). Combining collective intelligence methods that gather input from a diverse range of representative stakeholders in the design process ensures that scenariobased design thinking, incorporating stories about people and their activities (Caroll, 2000), is grounded in a comprehensive understanding of the societal issue. The advantage of scenario-based design is that it is helpful in dealing with complex problems in which the actors have diverging knowledge and backgrounds (Broome, 2009; Janssen et al., 2012; Warfield \& Cárdenas, 2002).

This study contributes to the literature by embracing contextuality and showing that collecting context-specific user needs results in a deeper and richer list of user needs that can be incorporated and integrated in the design of an open data platform that might be more valuable for citizens. For practice the scenario-based approach may help guide government agencies and designers in developing and implementing open data platforms.

The paper is organized as follows. In Section 2 we argue why collecting context-specific user requirements could be valuable for open platform design by comparing our approach with related work on user requirements. In this context we propose a collective intelligence scenario-based design methodology that will be described in Section 3. In Section 4, we describe how scenario-based design was conducted in our case study that focused on the societal issue population decline in Groningen, a province in The Netherlands. In Section 5 we will present the results of the collective intelligence scenario-based design in Groningen, followed by a discussion of these results. Finally, we draw conclusions and describe the limitations of our study.

\section{Collecting context-specific user requirements}

\subsection{Open data, users and societal issues}

Open data can be used as an instrument for public policy development and for gaining insight in and proposing solutions to societal problems (Janssen, 2011; Napoli \& Karaganis, 2010). Several scholars (Janssen, 2011; Napoli \& Karaganis, 2010) point out that open data are indispensable for public policy development and service delivery. It has the potential to facilitate citizen participation in which citizens e.g. help to set the policy agenda, propose policy solutions and shape the policy dialogue (Wijnhoven et al., 2015, p. 30; Taylor et al., 2014; Harrison \& Dayogo, 2014; OECD, 2001; Sieber \& Johnson, 2015).

Realizing these potential benefits of open data however prove difficult in practice. Several scholars have analyzed barriers to open data usage (Barry \& Bannister, 2014; Conradie \& Choennie, 2014; Dawes et al., 2016; Huijboom \& Van den Broek, 2011; Janssen et al., 2012; Zuiderwijk \& Janssen, 2014a, 2014b) and have pointed out that so far few platforms have been developed with the user in mind (Dawes \& Helbig, 2010; Patrício, Fisk, \& Cunha, 2008; Zuiderwijk, Janssen, Choenni, Meijer, \& Alibaks, 2012). They stress the importance of a user centered approach thereby identifying user requirements such as understandability, availability, quality, timeliness, but also value and usefulness (Lourenço, 2015; Zuiderwijk \& Janssen, 2014a，2014b; Zuiderwijk et al., 2012). Other scholars (Barry \& Bannister, 2014; Susha et al., 2015; Zuiderwijk \& Janssen, 2014a, 2014b) take government agencies as provider of open data as point of departure of analysis. Susha et al. (2015) for instance develop strategies for stimulating open data usage such as enhancing interaction with open data users and setting up an open data infrastructure that can leverage the capabilities of open data users. Furthermore, Sieber and Johnson (2015) distinguish models of open data provision in the current open data landscape: 1) "Data over the wall"; the status quo form of government supplying information; 2) "Code exchange" with government acting as data activist; 3) "Civic issue tracker", where government accepts direct feedback from citizens; and 4) Participatory open data, where government and citizens co-produce data. The assumption underlying the first two models is that open data can be used for every purpose and that patterns of usage cannot be predicted (Janssen, 2011). There are examples of useful apps for citizens created by tech-savvy developers that use government open data to generate content. But questions are raised whether this can truly enrich citizen-government relationships (Johnson \& Robinson, 2014). Releasing random datasets however does not automatically lead to them being useful or valuable for citizens (Sieber \& Johnson, 2015; Susha et al., 2015). There might not be a match between the data released and the data users are interested in related to a societal issue. According to Sieber and Johnson (2015) the last two models that emphasize interaction between users and providers are more in line with the realization of open government principles.

Hence, these models and approaches to enhance open data usage either take citizen users, data or government agencies as point of departure for analysis. Though important, these general patterns fail to acknowledge that open data usage also relates to a specific context. A contextual frame, is essential for motivating and engaging citizens and public administrators (Meijer, 2015, p. 205). Rather than just presenting information, a frame tells a story. It is a way to integrate citizens in public problem solving and value creation activities (Hutter, Fuller, \& Koch, 2011). Citizens engage in open government platforms because they have an intrinsic interest in the discussion of societal issues and generation of ideas for potential solutions (Hutter et al., 2011). Along these lines, Susha et al. (2015) argue that data publishing should not be supply or demand driven but should be problem driven to enable real-life problem-solving. They therefore indicate that governments in collaboration with citizens need to identify which information or data sets need to be published to help participants solve a societal issue (Susha et al., 2015). The participation model and problem driven model require collaboration spaces and virtual communities where users can exchange expertise, stimulate each other and can co-produce data (Sieber \& Johnson, 2015; Susha et al., 2015). Moreover, in these models both citizens and public administrators become users of the open data platform. However so far government portals often do not facilitate interaction, participation and collaboration (Sandoval-Almazan \& GilGarcia, 2012; Sivarajah et al., 2016).

The context-specific approach we propose (see Fig. 1) builds on the participatory open data model as pointed out by (Sieber \& Johnson, 2015) and the problem-driven approach suggested by Susha et al. (2015). A societal issue can be used as the story or the frame that connects open data with users. Our study takes into account a contextual frame, a societal issue (a), for collecting user requirements. Users (b) refer to both public administrators and citizens interested in a societal issue. The open data platform (c) refers to a platform that supports information, social interaction and collaboration and usability needs of users in relation to the societal issue.

\subsection{Open data as a service}

The service design literature stresses the importance of the context of use. An open data platform can be considered a service. A service consists of a combination of processes, people, skills and systems (Goldstein, Johnston, Duffy, \& Rao, 2002, p. 121). According to Kotamraju and Van der Geest (2012, p. 261) e-Government services 


\section{دريافت فورى ـ ـ متن كامل مقاله}

\section{ISIArticles}

مرجع مقالات تخصصى ايران

ل امكان دانلود نسخه تمام متن مقالات انكليسى ل امكان دانلود نسخه ترجمه شده مقالات ل يذيرش سفارش ترجمه تخصصى $\checkmark$ ل امكان جستجو در آرشيو جامعى از صدها موضوع و هزاران مقاله ل امكان دانلود رايكان r صفحه اول هر مقاله

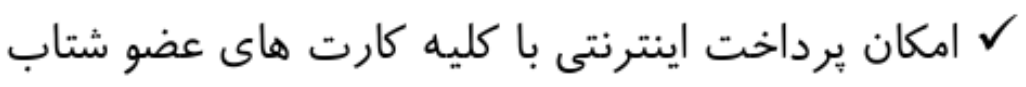
ل دانلود فورى مقاله پِ از برداخت آنلاين

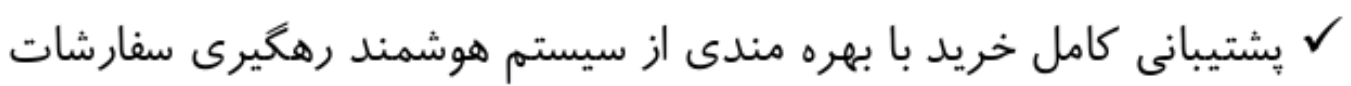

